\title{
Acidentes, adoecimento e morte no trabalho como tema de estudo da História
}

\author{
Ana Beatriz Ribeiro Barros Silva
}

\section{SciELO Books / SciELO Livros / SciELO Libros}

SILVA, ABRB. Acidentes, adoecimento e morte no trabalho como tema de estudo da História. In: OLIVEIRA, TB., org. Trabalho e trabalhadores no Nordeste: análises e perspectivas de pesquisas históricas em Alagoas, Pernambuco e Paraíba [online]. Campina Grande: EDUEPB, 2015, pp. 215240. ISBN 978-85-7879-333-3. Available from SciELO Books $<$ http://books.scielo.org $>$.

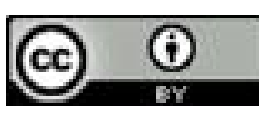

All the contents of this work, except where otherwise noted, is licensed under a Creative Commons Attribution 4.0 International license.

Todo o conteúdo deste trabalho, exceto quando houver ressalva, é publicado sob a licença Creative Commons Atribição 4.0.

Todo el contenido de esta obra, excepto donde se indique lo contrario, está bajo licencia de la licencia Creative Commons Reconocimento 4.0. 


\section{Acidentes, adoecimento e morte no trabalho como tema de estudo da História}

Ana Beatriz Ribeiro Barros Silva

\section{INTRODUÇÁO}

Durante o I Ciclo de Debates sobre História do Trabalho NDH-CH/UEPB, ocorrido em Guarabira, no Campus III da UEPB, no ano de 2013, tive a oportunidade de falar um pouco sobre minha pesquisa de Doutorado, em andamento, para uma plateia majoritariamente composta por alunos de graduaçáo, a maioria pouco familiarizada com os debates travados sobre a história do trabalho. Naquela ocasiáo, em uma mesa-redonda que tratava das relaçóes entre saúde e trabalho, abordei um dos pontos centrais da minha pesquisa: os acidentes e doenças do trabalho e as muitas possibilidades de pesquisa histórica que esse tema oferece.

Agora, nesta versão escrita, espero sistematizar a discussão em torno dos acidentes e doenças do trabalho e de seu potencial para nos revelar, entre outros aspectos, as condiçóes históricas de vida e trabalho a que os trabalhadores são submetidos, a organizaçáo do movimento operário, o posicionamento estatal, bem como as relaçóes entre capital e trabalho em um dado período de análise. Meu principal objetivo é tratar dos riscos, dos ritmos e das 
condições de vida e trabalho, que levam aos sinistros laborais e ao adoecimento, como uma questão histórica fundamental para entendermos as relaçóes sociais no capitalismo. Portanto, neste texto, não farei distinção entre os acidentes e as doenças do trabalho, haja vista que ambos são frutos do mesmo fenômeno: a exploração do trabalho.

Como discutirei neste artigo, os acidentes e as doenças do trabalho são a culminância de um longo e duro processo de exploração e das péssimas condiçóes de trabalho a que os trabalhadores são expostos e obrigados a suportar, por falta de outras opçóes que lhes garantam a sobrevivência. Além de uma espécie de "gota d'água" que impele os trabalhadores à ação, os acidentes e o adoecimento também revelam, da forma mais cruel possível, riscos que eram, até então, apenas cogitados, explicitando a violência do trabalho estranhado.

Este artigo está dividido em três partes. Na primeira, discuto sobre o parco debate acerca dos acidentes e das doenças de trabalho na historiografia brasileira do trabalho, apesar da relevância desta temática desde pelo menos o nascimento do capitalismo industrial. Na segunda parte, retomo as análises de Marx e Engels como forma de ressaltar o quanto a sinistralidade laboral é uma preocupação clássica na história do trabalho, embora tenha perdido sua preponderância nos debates mais recentes da área. Por fim, aponto alguns possíveis caminhos para pesquisas que se dediquem a examinar o problema dos acidentes, do adoecimento e da incapacidade para o trabalho sob enfoques diversos, com breves observaçóes sobre o caso brasileiro.

\section{Da invisibilidade dos acidentados e adoecidos pelo trabalho}

Acidentes de trabalho acontecem aos milhares todos os anos. Para termos uma ideia da dimensão desse problema, estatísticas do INSS apontam que ocorreram mais de 27 milhóes de acidentes de trabalho no Brasil, entre 1970 e 1990, que deixaram quase um milhão de trabalhadores incapacitados permanentemente e levaram cerca de 87 mil trabalhadores à morte. Mas essa náo 
é uma realidade de um passado relativamente distante. Só em 2011, foram registrados 711.164 acidentes de trabalho no Brasil $^{1}$, ainda que muitos casos náo sejam registrados ou caracterizados como tal2.

Todavia, os índices de acidentes registrados estáo longe de revelar a realidade da violência no trabalho. No Brasil, apenas os acidentes que são notificados no sistema previdenciário, através da CAT (Comunicação de Acidente de Trabalho), são contabilizados e utilizados como base para políticas públicas. Ainda, para os registros oficiais de índices de acidentes de trabalho e para o enquadramento no Seguro de Acidente de Trabalho, diversas categorias são excluídas, tais como: "o trabalhador avulso, os autônomos, trabalhadores domésticos, médicos residentes, servidores públicos civis e militares municipais, estaduais e federais, trabalhadores rurais empregados ou membros de unidade de economia familiar náo registrados e do mercado informal"3, que, juntos, correspondem a mais de $50 \%$ da população trabalhadora. Essa situação só contribui para ocultar a real dimensão dos acidentes e das doenças do trabalho no Brasil. Além disso, é difícil calcular a quantidade de ocorrências não notificadas, seja devido à falta de registro do trabalhador, por causa do desconhecimento das partes, do desencorajamento da comunicação de incidentes considerados leves e do ocultamento de sintomas por parte do trabalhador, por receio de retaliaçôes, entre outros fatores.

Se adicionarmos a esses números as doenças ocupacionais, mais silenciosas, de evolução mais demorada e dificilmente reconhecidas como decorrentes do trabalho, o problema da incapacidade - quando não da morte - decorrente do trabalho se torna ainda mais dramático. Mas, essa triste realidade, de pernas

1 MINISTÉRIO DO TRABALHO E EMPREGO et alii. Anuário Estatístico de Acidentes de Trabalho: AEAT 2011 - v.1. Brasília: MTE: MPS, 2012, p. 15.

2 Para uma discussão quanto à imprecisão dos métodos estatísticos sobre acidentes de trabalho, tome-se como exemplo o texto de BINDER, Maria C. Pereira; CORDEIRO, Ricardo. Sub-registro de acidentes de trabalho em localidade do Estado de São Paulo, 1997. Revista de Saúde Pública, São Paulo, v.37, n.4, p. 409-416, 2003.

3 MENDES, Jussara Maria Rosa. Acidente de trabalho (verbete). In: CATTANI, Antonio David; HOLZMANN (orgs.). Dicionário de trabalho e tecnologia. Porto Alegre: 2.ed. rev. e ampl., Zouk, 2011, p. 24-27. 
e braços amputados, de sequelas físicas e psicológicas e, até, de vidas que são ceifadas, é ardilosamente ignorada, nos mais diversos âmbitos de nossa sociedade. Conforme bem disse Chico Buarque, na canção Construção, lançada em 1971 e que sintetizou o drama social dos acidentes de trabalho produzidos pelos posicionamentos políticos e econômicos da ditadura militar que redundaram no "milagre" brasileiro, são muitos os que, ainda hoje, morrem "na contramão, atrapalhando o tráfego, o sábado, o passeio público".

$\mathrm{Na}$ historiografia do trabalho, o interesse pela sinistralidade laboral se deu de modo transversal, relacionado aos estudos acerca dos processos e das condiçóes de trabalho, especialmente no tocante às demandas e às lutas do movimento operário por melhorias em sua labuta diária. O surgimento de um campo específico dedicado ao estudo das condiçóes de vida e de trabalho e das formas de organização coletiva e política dos trabalhadores foi motivado, substancialmente, pelas questóes inerentes ao movimento operário. Assim, como observou Eric Hobsbawm, seu caráter politizado fez com que, muitas vezes, a história da classe operária tenha sido reduzida à história de seu movimento organizado ${ }^{4}$. Decorre daí a tradicional preferência, da parte dos historiadores do trabalho, por focar na organização coletiva dos trabalhadores, através de sindicatos, associaçóes, greves, partidos, ideias políticas, protestos, insurreiçóes, revoluçôes e outros temas ligados à questão da consciência da classe operária. Similarmente, a preferência pelos temas relacionados ao movimento operário propriamente dito também se fez sentir no Brasil já nos primeiros estudos desenvolvidos no país ${ }^{5}$, inclusive nos casos

4 HOBSBAWM, Eric J. Mundos do trabalho: novos estudos sobre história operária. Rio de Janeiro: 3.ed., Paz e Terra, 2000, p. 15-31.

5 Para um balanço das perspectivas intelectuais sobre o trabalho no Brasil, veja-se BATALHA, Cláudio H. M. A historiografia da classe operária no Brasil: trajetórias e tendências. In: FREITAS, Marcos Cezar (org.). A historiografia brasileira em perspectiva. São Paulo: 5.ed., Contexto, 2003, p. 145-158. 
tradicionalmente tratados como "regionais".

Os cortes temporais constituem outro aspecto característico da historiografia que não pode ser ignorado. Durante muito tempo, convencionou-se demarcar o início da história da classe trabalhadora brasileira no surgimento da República e no fim da escravidão formal ${ }^{7}$. Assim, de modo geral, há uma concentração de estudos dedicados à Primeira República e à Era Vargas, objetos principais da produção das décadas de 1980 e 1990. Destarte, observamos que, em relação à incapacidade para o trabalho, ainda há muito a ser feito. No Brasil, os raros estudos que analisam os acidentes de trabalho como consequência e fator revelador das formas de exploraçáo das relaçóes produtivas capitalistas restringem-se à Primeira República e ao Estado Novo ${ }^{8}$, ou se detêm a analisar a emergência de normas legais sobre a questáo 9

Ao longo dos anos 1990, houve um avanço em pesquisas sobre o tema, mas que não foi além do período de 1945-1964. Ainda são muito poucos os estudos históricos que abordam especificamente

6 Em um levantamento bibliográfico da produçáo acadêmica sobre o trabalho urbano no Brasil, fora do eixo Rio-São Paulo, de cerca de 900 títulos listados por Silvia Petersen, ao menos 429 são dedicados diretamente a esses temas. Cf. PETERSEN, Sílvia. Levantamento da produçáo bibliográfica e de outros resultados de investigaçáo sobre a história operária e o trabalho urbano fora do eixo Rio-São Paulo. Cadernos AEL, vol.14, n.26, 2009, p. 272-273.

7 O questionamento de 1889 , como marco inicial do processo de formação da classe trabalhadora brasileira, só passou a acontecer na década de 2000. Nesse sentido, ver, por exemplo, MATTOS, Marcelo Badaró. Escravizados e livres: experiências comuns na formação da classe trabalhadora carioca. Rio de Janeiro: Bom Texto, 2008.

8 Dentre esses estudos, citam-se: MOURA, Esmeralda B. Mulheres e menores no trabalho industrial: os fatores sexo e idade na dinâmica do capital. Petrópolis: Vozes, 1982; ARAVANIS, Evangelia. A industrialização no Rio Grande do Sul nas primeiras décadas da República: a organização da produçáo e as condiçôes de trabalho (1889-1920). Revista Mundos do Trabalho, v.2, n.3, p. 148-180, jan.-jul., 2010; SILVA, Maria Elisa Lemos Nunes da. Entre trilhos, andaimes e cilindros: acidentes de trabalho em Salvador (1934-1944). Salvador: Dissertação de Mestrado em História/UFBA, 1998; OLIVEIRA, Newton C. de. A economia do sinistro: contribuição ao estudo dos acidentes de trabalho na indústria têxtil durante o Estado Novo, 1937-1945. Niterói: Dissertação de mestrado em História/UFF, 1993; ALMEIDA, Anna Beatriz de Sá. Da moléstia do trabalho à doença profissional: contribuição ao estudo das doenças do trabalho no Brasil. Niterói: Dissertação de mestrado em História/ UFF, 1994.

9 GOMES, Angela de Castro. Burguesia e trabalho: política e legislação social no Brasil, 1917-1937. Rio de Janeiro: Campus, 1979; VIANNA, Luiz Werneck. Liberalismo e sindicato no Brasil. Belo Horizonte: 4.ed.rev., Ed. UFMG, 1999; FERRAZ, Eduardo Luís Leite. Acidentados e remediados: a Lei de Acidentes de Trabalho na Piracicaba da Primeira República (1919-1930). Revista Mundos do Trabalho, v.2, n.3, p. 206-235, jan.-jul., 2010. 
a classe operária nos períodos seguintes ao golpe de $1964^{10}$, apesar do reconhecimento da necessidade dos historiadores debaterem temas e processos recentes, tradicionalmente monopolizados por outras áreas do conhecimento ${ }^{11}$. Uma exceção é o chamado "novo sindicalismo" de fins da década de 1970 e início de 1980, tema que vem atraindo a atenção de vários pesquisadores, o que dá a falsa impressão de que, durante a maior parte da ditadura, os trabalhadores não resistiram nem se organizaram por seus direitos nos anos anteriores a esse ressurgimento.

Posto isso, mesmo com seus reconhecidos avanços qualitativos, a historiografia social do trabalho brasileira, tomada em seu conjunto, ainda apresenta muitas lacunas, que deveráo ser preenchidas pelos historiadores que pretendem ingressar nesse campo de estudo. Embora seja inegável a importância do estudo das formas de organização política dos trabalhadores, temos ainda muito a fazer acerca das condiçóes de vida e de trabalho daqueles que vivem da venda de sua força de trabalho, do seu cotidiano de exploraçáo e dos riscos a que são submetidos, seja no chão da fábrica, na lavoura ou na construção civil. Afinal, a maioria dos trabalhadores dedica parte considerável de suas existências trabalhando, e não, militando, o que evidencia a importância de estudos que analisem os processos e as condiçóes de trabalho e os mecanismos de exploração do trabalho através da extração de mais-valia, da qual as ocorrências de acidentes e doenças do trabalho não são mero efeito colateral, mas parte constituinte do processo de exploraçáo capitalista.

De modo análogo, apesar de sua frequência e gravidade, das consequências econômicas e sociais para as famílias trabalhadoras,

10 Dentre as exceçōes de historiadores que trataram o tema do novo sindicalismo, destacam-se: MATTOS, Marcelo Badaró. Novos e velhos sindicalismos no Rio de Janeiro, 1955-1988. Rio de Janeiro: Vício de Leitura, 1998 e COSTA, Hélio da. Em busca da memória: comissão de fábrica, partido e sindicato no pós-Guerra. São Paulo: Scritta, 1995; ABREU E LIMA, Maria do Socorro de. Construindo o sindicalismo rural: Lutas, partidos e projetos. $2^{\text {a }}$ ed. Recife: Editora Universitária da UFPE, 2012.

11 Sobre a discussão quanto à viabilidade e aos cuidados que o historiador deve ter ao tratar da história do presente (e até mesmo da história imediata), vejam-se, especialmente, CHAUVEAU, A.; TÉTARD, Ph. (orgs.). Questóes para a história do presente. Bauru: EDUSC, 1999 e HOBSBAWM, Eric. O presente como história. In: Sobre História. São Paulo: Cia. das Letras, 1998 , p. 243-255. 
sem falar da gritante subnotificação, os acidentes de trabalho são raramente debatidos pela sociedade em geral e poucos casos ganham espaço na imprensa, que normalmente só reserva notas rápidas para aqueles casos que são considerados mais graves. Destas observaçóes, alguns questionamentos precisam ser levantados: Por que os acidentes de trabalho acontecem e em tamanha proporção? Por que o trabalho, cada vez mais, adoece tantos trabalhadores? Por que o discurso da culpabilização das vítimas ainda tem tanta penetração e aceitação em nossa sociedade, inclusive entre os trabalhadores? Por que o drama dos trabalhadores incapacitados pelo trabalho náo é visto como um problema social? $\mathrm{O}$ que os acidentes podem nos revelar da dinâmica social entre capital e trabalho? E como o Estado medeia esta relaçáo? Estas são algumas das possíveis questóes que podem permear estudos acerca das condiçóes de trabalho, acidentes e doenças do trabalho e saúde do trabalhador.

\section{O problema dos acidentes de trabalho e da invalidez no capitalismo}

Acidentes e doenças do trabalho ocorrem em contextos históricos, relaçóes sociais e em condiçóes materiais determinadas, mas, como será discutido aqui, o crescente volume, a gravidade e a diversidade tipológica dos acidentes e das doenças do trabalho são um fenômeno eminente das relaçôes capitalistas de produção. Evidentemente, doenças, epidemias, acidentes, catástrofes - e o sofrimento e as mortes decorrentes desses eventos - marcaram a história da humanidade desde os tempos mais remotos. De modo análogo, descriçóes de doenças ocasionadas ou relacionadas ao trabalho remontam à Antiguidade e continuaram sendo objetos de análise desde então

Em papiros egípcios, textos judaicos, evidentemente em Hipócrates, Platão, Aristóteles, Plautus, Virgílio, Plínio, o velho, Lucrécio, chegando a Galeno, entre tantas citações ao longo da história. Pouco a pouco, ainda na Idade Média, 
as doenças relacionadas ao trabalho foram sendo observadas com maior detalhamento, com Avicena (980-1037), que descreveu a cólica plúmbica, com Dickerson observando a saúde de trabalhadores em catedrais, com Ellenborg (14401499), que escreve um livro sobre os riscos dos ourives, com Vigo, sobre a febre dos marinheiros e, entre outros, com Agrícola, sobre a asma dos mineiros ${ }^{12}$.

A ocorrência de acidentes de trabalho durante a execuçáo de grandes obras públicas, escavaçóes de minas e na navegação também foram recorrentes durante a História. A referência clássica nesse campo é a obra De Morbis Artificum Diatriba, publicada em 1700 pelo médico italiano Bernardino Ramazzini ${ }^{13}$. Considerado por muitos o 'pai da Medicina do Trabalho', Ramazzini foi o primeiro a sistematizar o conhecimento acumulado até entáo, o que é perceptível pela grande quantidade de citaçóes, além de propor o nexo entre ocupaçóes e determinados tipos de moléstia. Ramazzini relacionou os riscos à saúde dos trabalhadores ocasionados por produtos químicos, poeira, metais e outros agentes presentes no ambiente de trabalho. Ao todo, descreveu 54 tipos de ocupaçóes, dentre elas, as doenças dos mineiros, dos pintores, dos químicos, dos tipógrafos, dos tecelóes etc. e as possíveis moléstias decorrentes delas, dedicando-se principalmente às intoxicaçôes químicas e aos desconfortos do ambiente de trabalho. Sobre a relação entre trabalho - as artes - e as doenças e mortes decorrentes dele, Ramazzini afirmou: "É forçoso confessar que ocasionam náo pouco dano aos artesãos, certos ofícios que eles desempenham, onde esperavam obter recursos para sua própria manutençáo e de sua família, encontram graves doenças, e passam a amaldiçoar a arte à qual se haviam dedicado, afastando-se

\footnotetext{
12 VASCONCELLOS, Luís Calos Fadel de; PIGNATI, Wanderlei Antônio. Medicina do Trabalho: subciência ou subserviência? Uma abordagem epistemológica. Ciência \& Saúde Coletiva, v.11, n.4, 2006, p. 1112.

13 RAMAZZINI, Bernardino. As doenças dos trabalhadores. São Paulo: Fundacentro, 2000.
} 
do mundo dos vivos" ${ }^{14}$. O médico italiano ainda relacionou o estado de saúde dos indivíduos às condições em que viviam e à posição social e demonstrou preocupaçáo recorrente com a postura, o sedentarismo e o excesso de esforços no trabalho e suas consequências para a saúde dos trabalhadores.

Ramazzini desenvolveu seus estudos antes da Revolução Industrial e, obviamente, não examinou a disseminaçáo das relaçóes capitalistas de produçáo e de todas as grandes transformaçóes advindas deste marco. E o que mudou a partir do capitalismo industrial? Segundo Herval Pina Ribeiro, foi "a banalização e seletividade social maior das enfermidades e mortes prematuras por acidentes e doenças do trabalho, muitas entáo pouco ou nada conhecidas"15. Como este autor argumenta, os acidentes e as doenças do trabalho, ao contrário das doenças pestilenciais ou epidêmicas, são extremamente seletivos. Afinal, atingem os trabalhadores, especialmente os de determinadas categorias que estáo nos níveis mais baixos da hierarquia da divisão social do trabalho e que exercem as funçóes mais perigosas e insalubres, pelo simples fato de não poderem optar por outras funçôes mais seguras e mais bem remuneradas. Logo, assim como o trabalho modela a vida dos sujeitos, os acidentes e as doenças decorrentes dele são eventos marcantes que interrompem e desviam as trajetórias de milhares de trabalhadores e de suas famílias, muitas vezes, condenando cidadáos e cidadás a uma vida submissa e dependente da filantropia ou de políticas públicas no campo da previdência, que lhes garantem apenas, quando muito, a subsistência.

Na ordem capitalista, a Revolução Industrial é um marco fundamental, afinal, o crescimento alarmante do volume, a gravidade e a frequência dos acidentes de trabalho, desde a mecanização e o surgimento da indústria, são uma prova da complexa e conflituosa relação entre capital e trabalho. Desde entáo, novas formas de organização do trabalho, com vistas à acumulação através da exploração - por vezes 'científica' - da força de trabalho têm

14 Ibidem, p. 15.

15 RIBEIRO, Herval Pina. A violência oculta do trabalho: as lesôes por esforços repetitivos. Rio de Janeiro: Editora Fiocruz, 1999, p. 22. 
ampliado massivamente a sinistralidade laboral. Justifica-se: do ponto de vista dominante, os riscos seriam naturais e inerentes a algumas ocupaçóes ou funçóes, logo, os acidentes fariam parte de um lado triste, mas inevitável do desenvolvimento capitalista.

As transformaçóes no mundo do trabalho, desde a Revoluçáo Industrial, alteraram a incidência e a tipologia dos acidentes, bem como o surgimento e o reconhecimento das chamadas doenças ocupacionais. Para entendermos a relevância dos acidentes e doenças do trabalho e a questáo do não-trabalho ocasionado pela incapacidade, devemos ter em mente a centralidade do trabalho nas sociedades capitalistas. Indubitavelmente, o estabelecimento do capitalismo industrial e sua proliferaçáo para os mais distantes pontos do globo é um dos marcos fundamentais da conflituosa relação entre capital e trabalho e a questáo social dela decorrente. Entre outras tentativas de compreender a pobreza e a questão social durante o Século XIX, Friederich Engels e Karl Marx foram muito além de seus contemporâneos adeptos do liberalismo, que se limitavam a relacionar a pobreza à suposta vagabundagem e preguiça dos trabalhadores para explicar a relação entre as desigualdades e o capitalismo.

Em especial, a obra $A$ situação da classe trabalhadora na Inglaterra, de Engels, diferia das análises de seus antecessores e contemporâneos por tratar a classe operária no âmbito da evoluçáo do capitalismo industrial, com foco no impacto social causado pela industrialização. Engels foi um observador astuto e acompanhou o centro nevrálgico da Revoluçáo Industrial de perto. Em seu livro, examinou as profundas transformaçóes e a degradação do nível de vida da classe operária inglesa. Para Engels, a industrializaçáo reduziu os trabalhadores "ao papel de simples máquinas, arrebatando-lhes os últimos vestígios de atividade independente" 16 .

Conforme a análise de Engels, os operários tinham que trabalhar diariamente até a completa exaustáo física e moral. Tais condiçóes de vida e de trabalho, com pouca e péssima comida,

16 ENGELS, Friedrich. A situação da classe trabalhadora na Inglaterra. São Paulo: 2.ed., Global Editora, 1985, p. 14. 
trancafiados em lugares insalubres, seja no trabalho ou em suas habitaçóes, só podia levar a doenças devastadoras, como a tuberculose e o tifo. Engels notava certo "ar tísico" nas pessoas, especialmente em Londres: extremamente magras, com o peito estreito, olhos escavados e rostos "inexpressíveis, incapazes da menor energia" ${ }^{17}$. Devido à sua indigesta e parca alimentação, diversas doenças dos órgãos digestivos eram muito comuns, como as escrófulas e o raquitismo.

O trabalho em si era monótono, repetitivo e embrutecedor, pois não permitia nenhuma tarefa intelectual ou criativa. A duração do trabalho podia chegar até 16 horas diárias, sem contar os intervalos para as refeiçóes. As máquinas foram paulatinamente eliminando o operariado adulto das fábricas, que ia sendo substituído por mulheres e crianças que, além de mais hábeis na lida com a maquinaria, eram mais rentáveis, haja vista que, em decorrência da dominação masculina e patriarcal que imperava na sociedade inglesa, recebiam salários bem abaixo dos pagos ao operário adulto do sexo masculino. A violência era usada ocasionalmente contra os operários, sobretudo contra as crianças. Os capitalistas exploravam o trabalho ao máximo, criando jornadas noturnas, o que fazia com que algumas fábricas funcionassem ininterruptamente.

De acordo com o Factories Inquiry Commission, de 1833, analisado por Engels, entre os operários, havia um número elevado de enfermos, cuja doença provinha, além das péssimas condições de vida, das longas horas de trabalho. Desvios da coluna vertebral e deformaçóes nas pernas eram as mais comuns, provenientes, segundo a comissão, da sobrecarga física exigida pelo trabalho prolongado.

$\mathrm{O}$ próprio Engels relatou: "raramente andei por Manchester sem cruzar com três ou quatro defeituosos, sofrendo precisamente das deformaçóes da coluna vertebral e das pernas que acabam de ser descritas". A exigência de que ficassem longas horas em pé, sem poder ao menos encostar-se, o que poderia custar uma punição, 
era o principal causador das deformaçóes, sem falar na atmosfera quente, úmida e asfixiante das fábricas. Nos relatórios, os médicos ressaltavam a "falta de resistência [dos operários] às doenças, um estado depressivo geral, afetando todas as atividades vitais, um relaxamento persistente das capacidades intelectuais e físicas"18.

Finalmente, o trabalho nas máquinas ocasionava um número elevado de acidentes que levavam à incapacidade parcial, total ou à morte. $\mathrm{O}$ mais frequente era o corte ou esmagamento de um dedo, mas a perda da mão ou do braço também ocorria, embora com menos constância. Muitas vezes, os operários iam a óbito devido ao tétano que adquiriam depois dos acidentes mais corriqueiros e considerados de menor gravidade. As mutilações decorrentes de acidentes de trabalho também chamaram a atenção de Engels: "Em Manchester, podem-se ver, além de muitos aleijados, um grande número de mutilados; um perdeu todo o braço ou o antebraço, outro o pé, ainda outro a metade da perna; é como estar no meio de um exército que volta de uma batalha" 19 .

Os acidentes mais graves e que ocasionavam mortes violentas eram noticiados pelos jornais, mas os menores sequer eram mencionados. Segundo Engels, as correias que transmitiam energia às máquinas eram as mais perigosas: "Quem é apanhado por essas correias é levado pela força motriz com a rapidez de um raio, o corpo é lançado para o teto, depois contra o cháo com uma tal violência que raramente fica intacto um osso e a morte é instantânea" ${ }^{20}$. Foram muitas as mortes causadas pelo trabalho industrial mencionadas por Engels, entre elas, a de uma criança que morreu de tétano, depois de sua máo ter sido esmagada por uma engrenagem; um rapaz apanhado e lançado por uma roda, que morreu completamente esmagado; a de uma jovem de Oldham, que foi apanhada por uma correia que a fez dar cinquenta voltas, e nenhum osso ficou intacto; um torneiro que foi arrastado por uma correia e morreu com todas as costelas partidas... Em casos como esses, os capitalistas pagavam os custos médicos e, quando muito, o

18 Ibidem, p. 178.

19 Ibidem, p. 187.

20 Ibidem, p. 187. 
salário no período de tratamento, e não carregavam nenhuma responsabilidade legal quando o acidente levava à incapacidade para $\mathrm{o}$ trabalho. Se esse fosse o caso, os trabalhadores não tinham direito a qualquer tipo de auxílio e só podiam contar com a caridade alheia.

Considero os acidentes e as doenças do trabalho como a culminância de um longo processo de exploração e expropriação da dignidade humana, que assumiu sua forma mais manifesta no início do capitalismo industrial. Apesar dos relatos acerca dos impactos dilacerantes da Revolução Industrial sobre a classe trabalhadora inglesa terem sido reportados aqui através de Engels, sua análise não foi, de forma alguma, um caso isolado. Sua obra faz parte de uma tradição muito mais ampla de estudos e descriçóes do horror das cidades industriais e de Manchester, em particular; alguns, conhecidos por Engels, outros, não ${ }^{21}$, além das tantas análises posteriores ao autor.

Conforme analisou Thompson, apesar de certa melhoria no padrão material médio dos trabalhadores, a Revolução Industrial submeteu a maioria à intensificação da exploraçáo econômica, à insegurança, opressão política e ao aumento da miséria, o que fez com que a expansão industrial fosse sentida como uma "experiência catastrófica" para a maioria dos trabalhadores que viveram aquele período $^{22}$. Eric Hobsbawm sintetiza a insegurança dos daquele período, em suas diversas facetas:

Se um único fator dominava a vida dos trabalhadores do Século XIX, esse fator era a 'insegurança'. Eles não sabiam no principio da semana quanto iriam levar para casa na sexta-feira. Eles não sabiam quanto iriam durar no emprego presente, ou se viessem a perdê-lo, quando voltariam a encontrar um novo trabalho e em que condiçóes. Eles não sabiam que acidentes ou doenças iriam afetá-los, e embora soubessem que algum

21 HUNT, Tristram. Comunista de casaca: a vida revolucionária de Friedrich Engels. Rio de Janeiro: Record, 2010, p. 91-133.

22 THOMPSON, E. P. A formaçáo da classe operária inglesa - v. 2. Rio de Janeiro: Paz e Terra, 1987, p. 11-38. 
dia no meio da vida - talvez 40 anos para os trabalhadores não especializados, talvez 50 anos para os especializados - iriam se tornar incapazes para o trabalho pleno e adulto, não sabiam o que iria acontecer então entre esse momento e a morte ${ }^{23}$.

Desde a Revolução Industrial, as condições de vida e de trabalho levaram ao descontentamento do proletariado, e a luta pela melhoria de sua situação se tornou uma plataforma constante de reivindicaçôes até os nossos dias, o que levou à constituiçáo de movimentos de radicalismo, tumultos, movimentos organizados, como o luddismo e o cartismo, greves e tentativas de levantes armados, além do fato de que foi em meio a esses conflitos que se formou - e ainda se forma - a classe operária propriamente dita, que, como nos ensinou Thompson, esteve presente em seu próprio fazer-se ${ }^{24}$.

Historicamente, as máquinas foram introduzidas em tempos de prosperidade e questionadas em tempos de crise, principalmente devido ao desemprego resultante da substituição de mãode-obra humana pela maquinaria. Um aspecto importante nessa questão é a função política da divisão do trabalho e da maquinaria como instrumentos de disciplinamento dos trabalhadores, por possibilitar náo apenas o controle das matérias-primas, dos produtos, mas também, principalmente, dos ritmos dos homens e de seus corpos. Como assinalou Michelle Perrot,

\begin{abstract}
A máquina é um instrumento de disciplina cujos efeitos precisam ser vistos concretamente: materialmente no espaço remodelado da fábrica e no emprego do tempo, fisicamente ao nível do corpo do trabalhador, de que a história tradicional das técnicas nos fala táo pouco ${ }^{25}$.
\end{abstract}

23 HOBSBAWM, Eric. A Era do Capital: 1848-1875. Rio de Janeiro: Paz e Terra, 1977, p. 231. (Grifo meu).

24 THOMPSON, E. P. A formaçáo da classe operária inglesa - 3 v. Rio de Janeiro: Paz e Terra, 1987.

25 PERROT, Michelle. Os excluídos da História: operários, mulheres e prisioneiros. Rio de Janeiro: Paz e Terra, 2001, p. 24. 
É bastante extensa a historiografia internacional que trata da relaçáo do trabalhador com a máquina desde os princípios da Revolução Industrial. A maquinaria impunha novos ritmos, exigia do trabalhador novas habilidades e retirava-lhes o tempo de descanso ou a liberdade de optar por determinada parte do processo produtivo. Estranhamento, exaustáo física e mental, acidentes, amputaçóes e mortes fazem parte da mesma equaçáo no processo de acumulaçáo capitalista.

E qual a relaçâo entre a incapacidade causada para/pelo trabalho e a exploração capitalista? As análises elaboradas por Marx e Engels buscaram compreender a origem da pobreza e das desigualdades sociais nas sociedades de capitalismo avançado do Século XIX, na perspectiva da economia política. De modo geral, segundo suas análises, o pauperismo advém da exploração do proletariado através da extração de mais-valia e da existência de um "exército industrial de reserva", que pressiona os salários pagos aos trabalhadores para baixo. Logo, o empobrecimento dos trabalhadores é inerente ao sistema capitalista e condição para sua reproduçáo. No capitalismo, a força de trabalho é uma mercadoria cuja utilizaçáo aumenta o valor de outras mercadorias, ao passo que o trabalho é a fonte do valor através do qual o valor de uso das mercadorias é alterado, ou seja, acrescentado de valor. Consequentemente, o valor de uso da força de trabalho é sua capacidade de produzir valor.

De acordo com Marx, devido ao objetivo precípuo do capitalismo ser a extraçáo incessante de mais-valia, pouca ou nenhuma atenção era dada à manutenção e à qualidade de vida da força de trabalho. Afinal, quanto maior a jornada de trabalho, maior será a extração de mais-valia:

Em vez da conservação normal da força de trabalho determinar aqui o limite da jornada de trabalho, é, ao contrário, o maior dispêndio possível diário da força de trabalho que determina, por mais penoso e doentiamente violento, o 
limite do tempo de descanso do trabalhador. $\mathrm{O}$ capital não se importa com a duração de vida da força de trabalho. O que interessa a ele, pura e simplesmente, é um maximum de força de trabalho que em uma jornada de trabalho poderá ser feita fluir. Atinge esse objetivo encurtando a duração da força de trabalho, como um agricultor ganancioso que consegue aumentar o rendimento do solo por meio do saqueio da fertilidade do solo $^{26}$.

Ressalte-se, contudo, que a extração de mais-valia está longe de ser um dado mecânico: é a partir da negociação entre comprador e vendedor da força de trabalho e dos conflitos decorrentes da intensidade e das condiçóes de trabalho, do salário e do padrão de vida que origina a luta de classes, o motor da história para o marxismo. É desse conflito entre classes antagônicas, com interesses díspares, que se estruturam os aspectos técnicos e sociais da produção capitalista. Do ponto de vista marxista, a venda de força de trabalho aliena o trabalhador de sua capacidade criativa e de qualquer controle sobre o produto do seu trabalho. No capitalismo, a exploração toma a forma de extração de mais-valia, mas as bases e a forma como se dá essa exploração são frutos de constantes negociaçóes e conflitos:

[...] a produção de um excedente torna possível a exploração, que é o fundamento da sociedade de classes. A exploração ocorre quando um setor da população produz um excedente cuja utilização é controlada por outro setor. As classes, na teoria marxista, só existem nas relaçóes que mantêm umas com as outras, e essa relação gira em torno da forma de exploração que tem lugar em um determinado modo de produção. A exploração

26 MARX, Karl. O Capital: Crítica da economia política - Livro I, v.1. São Paulo: Abril Cultural, 1983, p. 379. 
dá origem à luta de classes ${ }^{27}$.

Como demonstra Thompson, a relação capitalista de exploração não se faz sem resistências, sejam elas explícitas ou silenciosas, produzindo formas históricas de conflitos sociais e políticos indeterminados aprioristicamente. Afinal,

nenhum trabalhador conhecido pelos historiadores jamais permitiu que a mais-valia lhe fosse arrancada do couro sem encontrar uma maneira de reagir (há muitas maneiras de 'fazer cera'), e, paradoxalmente, por sua reação, as tendências foram desviadas e as 'formas de desenvolvimento' se processaram de maneiras inesperadas ${ }^{28}$.

Assim, cabe perguntar como essa relação dinâmica entre capital e trabalho se expressou no tocante às condiçóes de trabalho e aos acidentes e doenças decorrentes. Os acidentes e as doenças ocupacionais têm o poder de revelar riscos até então naturalizados ou ignorados, bem como condiçôes adversas para a saúde e a segurança dos trabalhadores, o que deu origem a diversas reivindicaçóes operárias por melhores condiçóes de trabalho ao longo da história. Os acidentes e os desastres nas minas, no início da industrialização, levaram ao crescimento do número de viúvas, órfãos e de trabalhadores inválidos desamparados, o que provocou críticas ao sistema industrial. Em pouco tempo, as discussóes sobre os acidentes náo se limitavam mais aos locais de trabalho e tornaram-se pauta na arena política. Consequentemente, normas legais, direitos básicos e sistemas de inspeção foram elaborados com vistas a estabelecer um limite na exploração do trabalho, com vistas a deter a sua completa deterioração.

27 HIMMELWEIT, Susan. Exploração (verbete) In: BOTTOMORE, Tom (org.). Dicionário do pensamento marxista. Rio de Janeiro: Jorge Zahar Editor, 1988, p. 145.

THOMPSON, E. P. A miséria da teoria. Rio de Janeiro: Zahar, 1981, p.170. 


\section{Alguns caminhos possíveis de pesquisa}

$\mathrm{O}$ advento do sistema capitalista trouxe mudanças profundas para as sociedades sob sua influência: divisão social do trabalho, vigilância hierarquizada, longas jornadas de trabalho em turnos diurnos e noturnos, salários desiguais, trabalho infantil e, mais recentemente, a precarização e a flexibilização da força de trabalho. E como consequência da exploração, das péssimas condiçóes de vida e de trabalho e dos embates provocados pelas transformações das relações sociais desde a Revolução Industrial, tem-se também o surgimento e vertiginoso aumento dos acidentes e doenças do trabalho tal como conhecemos hoje.

Acidentes de trabalho são fenômenos socialmente produzidos e, como tal, podem ser esclarecedores das dinâmicas e das demandas políticas de uma sociedade, para as quais o Estado pode, ou não, responder por meio de políticas públicas ${ }^{29}$. Historicamente, o confronto entre os liberais e o movimento operário explicitou a relevância da questão social, o que resultou no encaminhamento de reformas que levaram ao reconhecimento dos direitos sociais voltados para limitar a exploração dos trabalhadores e protegê-los das consequências da incapacidade para o trabalho devido às doenças, à velhice e aos acidentes do trabalho. Na dinâmica da luta de classes, os Estados, diante dessas novas demandas, tiveram que agir e ceder aos reclames pela criação e ampliação de uma legislação social e trabalhista, bem como pela efetivação de políticas públicas de assistência à saúde do trabalhador.

Frente ao processo de exploração capitalista que levou ao exponencial aumento de acidentes e doenças do trabalho, bem como ao desenvolvimento de saberes científicos que visavam controlar esses eventos - tais como a Medicina e a Psicologia do trabalho, a Ergonomia, a Engenharia de segurança, entre outras áreas marcadamente vinculadas à lógica burguesa em sua nascença - é evidente que os trabalhadores se articularam com vistas a, pelo menos, refrear o sucateamento de seu maior bem, dentro do sistema capitalista: sua força de trabalho. Como consequência

29 AUGUSTO, Maria Helena Oliva. Políticas públicas, políticas sociais e políticas de saúde: algumas questóes para reflexão e debate. Tempo Social, n. 1, v.2, p. 105-119, 2 sem. 1989. 
desse processo, a legislação social de proteção ao trabalhador incapacitado para o trabalho, principalmente quando resultado de acidentes de trabalho, foi uma das primeiras a serem erigidas no mundo capitalista ocidental, a partir do Século XIX.

No Brasil da Primeira República, as relaçôes de trabalho eram marcadamente liberais. Consequentemente, apesar da forte pressão operária, os empresários resistiram por muito tempo a admitir uma legislação de proteção ao trabalhador. Em um contexto internacional de questionamento do capitalismo, especialmente em decorrência da Revolução Bolchevique de 1917 e em meio a grandes ondas grevistas em todo o Brasil, só em 1918 foi que o Congresso e os industriais brasileiros aceitaram discutir, pela primeira vez, com alguma seriedade, sobre as proposiçóes de um Código do Trabalho e o consequente reconhecimento dos direitos sociais dos trabalhadores.

Não por mera coincidência, no Brasil, a primeira lei para regulamentar as relaçóes de trabalho foi a que reconhecia a responsabilidade potencial do empregador de indenizar o empregado em caso de acidente no trabalho. O Decreto-lei 3.724, de 1919, atribuía os acidentes de trabalho às moléstias contraídas exclusivamente pelo exercício do trabalho e excluía as doenças decorrentes das condiçôes de trabalho e de vida do trabalhador. Logo, não eram considerados fatores como má nutrição, fadiga e condiçóes precárias de moradia como coadjuvantes da ocorrência de acidentes e doenças do trabalho.

A lei de acidentes de trabalho de 1919 inspirou-se na "doutrina objetiva do risco profissional", que, em linhas gerais, retira a responsabilidade do empregador e/ou da sociedade pelos acidentes de trabalho. Em suma, considerava-se o acidente como inerente ao trabalho, e a indenização ao trabalhador, como uma "concessão de privilégios sociais". Os empregadores ficavam resguardados nos casos em que os acidentes tivessem acontecido por negligência ou incompetência do trabalhador. Assim, os acidentes de trabalho permaneceram na esfera dos conflitos privados entre patróes em empregados e limitados ao pagamento ou não de indenizaçóes por um curto período. Nesse sistema, os patróes indenizariam seus 
empregados por um ano, através de companhias seguradoras privadas, autorizadas a funcionar no ramo de acidentes. Esse sistema, além de atender parcialmente às exigências de leis sociais, trouxe grandes vantagens econômicas para o empresariado, o que explica sua sobrevivência até a década de 1960, apesar de tentativas de reforma $^{30}$. A teoria do risco objetivo só foi alterada pela teoria do risco social através da Lei 5.316, de 14 de julho de 1967.

Mais difícil de ser comprovado do que o acidente, o adoecimento em virtude do trabalho gerou discussóes fundamentais para consolidar uma proteçáo social mais ampla ao trabalhador incapacitado. Em seus estudos, Anna Beatriz de Sá Almeida ${ }^{31}$ investigou as políticas e os debates intelectuais que envolveram o tema 'doenças do trabalho no Brasil', enfocando a primeira metade do Século XX. Diferentes atores se envolveram na discussão e na consolidação do que eram doenças do trabalho: médicos, juízes, empresários, sindicalistas, trabalhadores etc. Como a autora demonstrou, as disputas para se constituir um nexo causal entre a doença e o trabalho foram intensas, porquanto os diferentes grupos sociais defendiam seus próprios interesses. Era difícil para os empresários, por exemplo, reconhecerem a ligação entre as doenças e as precárias condiçóes de vida e trabalho, como no caso da ligação entre a fadiga e a tuberculose. $\mathrm{O}$ problema era provar a relação de causalidade entre trabalho e doença, terreno bastante movediço e aberto a diversas interpretaçóes, que produzia debates acalorados dentro e fora da comunidade médica.

Concomitantemente, ganhavam cada vez mais destaque as ações relativas a indenizaçóes por doenças ou acidentes, movidas por trabalhadores contra seus empregadores, inicialmente na Justiça comum e, posteriormente, na Justiça do Trabalho. Travava-se uma luta entre trabalhadores e patróes, agora na arena jurídica,

30 Gomes, Angela de Castro, op. cit., p. 55-76.

31 ALMEIDA, Anna Beatriz de Sá. Da moléstia..., op. cit.; ALMEIDA, Anna Beatriz de Sá. As parcelas (in)visíveis da saúde do trabalhador: uma contribuição da medicina do trabalho no Brasil (1920-1950). Niterói: Tese de Doutorado em História/UFF, 2004; ALMEIDA, Anna Beatriz de Sá. Doenças e trabalho: um olhar sobre a construção da especialidade medicina do trabalho. In: NASCIMENTO, Dilene Raimundo do; CARVALHO, Diana Maul de (orgs.). Uma história brasileira das doenças. Rio de Janeiro: Mauad X, 2006. 
intermediadas pelo Poder Judiciário ${ }^{32}$. Nesses embates, conforme observa Almeida, era comum o argumento de culpabilizar o trabalhador, responsabilizando-o pela a doença ou acidente, em decorrência de suas condiçóes de vida e, muitas vezes, de seu alegado desregramento moral e as imprudências cometidas fora do ambiente de trabalho, como bebedeiras e comportamento sexual inadequado: "No discurso dos industriais, de alguns juízes e de higienistas, as imagens do trabalhador e das suas condiçóes de vida estavam associadas à promiscuidade, doença e sujeira"33.

É preciso destacar que, historicamente, o discurso da inevitabilidade dos acidentes de trabalho vem sendo utilizado por empregadores, especialistas em higiene e segurança do trabalho e por órgãos estatais como justificativa para a incapacidade laboral. Em sua versão mais tacanha, os acidentes de trabalho seriam o resultado da imprudência e da ignorância dos trabalhadores, por vezes acusados de automutilação visando indenizaçóes indevidas. Como analiso em minha tese de Doutorado, esse discurso de culpabilização do trabalhador foi fortalecido durante a ditadura militar brasileira (1964-1985), especialmente através da Fundacentro $^{34}$, fundada em 1966 com o objetivo de identificar causas e propor soluçóes para a melhoria da higiene e a segurança do trabalho, objetivando reduzir a sinistralidade laboral. Essa instituição foi responsável pela disseminação da ideia de que mais de $80 \%$ dos acidentes eram resultado da imperícia ou ignorância dos trabalhadores, fundamentando "cientificamente" a noção do "ato inseguro" ${ }^{35}$. O discurso de culpabilização do trabalhador foi extremamente eficiente e, ainda hoje, é fortemente reproduzido pelos próprios trabalhadores ${ }^{36}$.

32 Por exemplo, CORRÊA, Larissa Rosa. A tessitura dos direitos: patrôes e empregados na Justiça do Trabalho, 1953-1964. São Paulo: LTr, 2011. Atualmente, a utilizaçáo de processos trabalhistas vem se consolidando cada vez mais na pesquisa histórica, conforme demonstram diversos capítulos deste próprio livro.

33 ALMEIDA, Anna Beatriz de Sá. Doenças..., op. cit., p. 203-205.

34 Fundação Centro Nacional de Segurança e Higiene do Trabalho, posteriormente renomeada como Fundação Jorge Duprat Figueiredo de Segurança e Medicina do Trabalho, em homenagem ao empresário e diretor da Fundacentro Jorge Duprat Figueiredo.

35 COHN, Amélia; KARSCH, Úrsula S.; HIRANO, Sedi; SATO, Ademar K. Acidentes de trabalho: uma forma de violência. São Paulo: Brasiliense/CEDEC, 1985.

36 OLIVEIRA, Fábio. A persistência da noção de ato inseguro e a construção da culpa: os discursos sobre acidentes de trabalho em uma indústria metalúrgica. Revista Brasileira de Saúde Ocupacional (RBSO), São Paulo, v. 32, n.115, p. 19-27, 2007. 
Como pesquisadora do tema, acredito que ainda temos muito a avançar no sentido de um maior entendimento da questão da incapacidade para o trabalho. Com frequência, tamanho problema social é relegado ao cálculo burocrático dos índices de acidentes registrados, afastamentos por incapacidade definitiva ou temporária e o volume de gastos com previdência e assistência. Apesar da ocultação e da subnotificação, os índices de incapacidade em decorrência do trabalho são muito evidentes. Entretanto, é preciso ir além da frieza dos índices, que disfarçam, sob a frieza dos números, a dureza que é ser trabalhador no Brasil. O mascaramento do sofrimento, da morte e do adoecimento no trabalho, mesmo dos acidentes mais catastróficos e difíceis de ignorar, ainda é uma triste realidade que urge por uma compreensão mais aprofundada - e por que não dizer? - politizada.

Afinal, como bem coloca Giovanni Alves, a saúde do trabalhador é um tema crucial, que expóe, de forma contundente, "a miséria humana sob as condiçôes de exploração do capital”. Por isso mesmo, essa discussão crítica não pode ser relegada apenas aos médicos e aos demais especialistas de plantão, "proprietários do saber competente, atribuiçáo ideológica que lhes confere o poder de ocultar as raízes sociais do adoecimento do homem que trabalha" ${ }^{37}$. Voltemo-nos a estas raízes.

\section{REFERÊNCIAS}

ABREU E LIMA, Maria do Socorro de. Construindo o sindicalismo rural: Lutas, partidos e projetos. $2^{\mathrm{a}}$ ed. Recife: Editora Universitária da UFPE, 2012.

ALMEIDA, Anna Beatriz de Sá. As parcelas (in)visíveis da saúde do trabalhador: uma contribuição da medicina do trabalho no Brasil (1920-1950). Niterói: Tese de Doutorado em História/UFF, 2004.

37 ALVES, Giovanni. Dimensóes da precarizaçáo do trabalho: ensaios de Sociologia do Trabalho. Bauru, SP: Projeto Editorial Práxis, 2013, p. 127. 
ALMEIDA, Anna Beatriz de Sá. Da moléstia do trabalho à doença profissional: contribuição ao estudo das doenças do trabalho no Brasil. Niterói: Dissertação de mestrado em História/ UFF, 1994.

ALMEIDA, Anna Beatriz de Sá. Doenças e trabalho: um olhar sobre a construção da especialidade medicina do trabalho. In: NASCIMENTO, Dilene Raimundo do; CARVALHO, Diana Maul de (orgs.). Uma história brasileira das doenças. Rio de Janeiro: Mauad X, 2006.

ALVES, Giovanni. Dimensóes da precarizaçáo do trabalho: ensaios de Sociologia do Trabalho. Bauru, SP: Projeto Editorial Práxis, 2013.

ARAVANIS, Evangelia. A industrialização no Rio Grande do Sul nas primeiras décadas da República: a organização da produção e as condiçôes de trabalho (1889-1920). Revista Mundos do Trabalho, v.2, n.3, p.148-180, jan/jul., 2010.

AUGUSTO, Maria Helena Oliva. Políticas públicas, políticas sociais e políticas de saúde: algumas questôes para reflexão e debate. Tempo Social, n.1, v.2, p.105-119, 1989.

BATALHA, Cláudio H. M. A historiografia da classe operária no Brasil: trajetórias e tendências. In: FREITAS, Marcos Cezar (org.). A historiografia brasileira em perspectiva. 5.ed. São Paulo: Contexto, 2003, p. 145-158.

BINDER, Maria C. Pereira; CORDEIRO, Ricardo. Sub-registro de acidentes de trabalho em localidade do Estado de São Paulo, 1997. Revista de Saúde Pública, São Paulo, v.37, n.4, p. 409-416, 2003.

CHAUVEAU, A.; TÉTARD, Ph. (orgs.). Questóes para a história do presente. Bauru: EDUSC, 1999. 
COHN, Amélia; KARSCH, Úrsula S.; HIRANO, Sedi; SATO, et al. Acidentes de trabalho: uma forma de violência. São Paulo: Brasiliense/CEDEC, 1985.

CORREAA, Larissa Rosa. A tessitura dos direitos: patrốes e empregados na Justiça do Trabalho, 1953-1964. São Paulo: LTr, 2011.

COSTA, Hélio da. Em busca da memória: comissão de fábrica, partido e sindicato no pós-Guerra. São Paulo: Scritta, 1995.

ENGELS, Friedrich. A situação da classe trabalhadora na Inglaterra. São Paulo: 2.ed., Global Editora, 1985.

FERRAZ, Eduardo Luís Leite. Acidentados e remediados: a Lei de Acidentes de Trabalho na Piracicaba da Primeira República (1919-1930). Revista Mundos do Trabalho, v.2, n.3, p.206235, jan.-jul., 2010.

GOMES, Angela de Castro. Burguesia e trabalho: política e legislação social no Brasil, 1917-1937. Rio de Janeiro: Campus, 1979.

HIMMELWEIT, Susan. Exploração (verbete) In: BOTTOMORE, Tom (org.). Dicionário do pensamento marxista. Rio de Janeiro: Jorge Zahar Editor, 1988, p.144-145.

HOBSBAWM, Eric J. Mundos do trabalho: novos estudos sobre história operária. 3.ed. Rio de Janeiro: Paz e Terra, 2000.

HOBSBAWM, Eric. A Era do Capital: 1848-1875. Rio de Janeiro: Paz e Terra, 1977.

HOBSBAWM, Eric. O presente como história. In: Sobre História. São Paulo: Cia. das Letras, 1998, p.243-255. 
HUNT, Tristram. Comunista de casaca: a vida revolucionária de Friedrich Engels. Rio de Janeiro: Record, 2010.

MARX, Karl. O Capital: Crítica da economia política - Livro I, v.1. São Paulo: Abril Cultural, 1983.

MATTOS, Marcelo Badaró. Escravizados e livres: experiências comuns na formação da classe trabalhadora carioca. Rio de Janeiro: Bom Texto, 2008.

MATTOS, Marcelo Badaró. Novos e velhos sindicalismos no Rio de Janeiro, 1955-1988. Rio de Janeiro: Vício de Leitura, 1998.

MENDES, Jussara Maria Rosa. Acidente de trabalho (verbete). In: CATTANI, Antonio David; HOLZMANN (orgs.). Dicionário de trabalho e tecnologia. 2.ed. Porto Alegre: rev. e ampl., Zouk, 2011, p. 24-27.

MINISTÉRIO DO TRABALHO E EMPREGO et al. Anuário Estatístico de Acidentes de Trabalho: AEAT 2011 - v.1. Brasília: MTE: MPS, 2012, p.15.

MOURA, Esmeralda B. Mulheres e menores no trabalho industrial: os fatores sexo e idade na dinâmica do capital. Petrópolis: Vozes, 1982.

OLIVEIRA, Fábio. A persistência da noção de ato inseguro e a construção da culpa: os discursos sobre acidentes de trabalho em uma indústria metalúrgica. Revista Brasileira de Saúde Ocupacional (RBSO), São Paulo, v.32, n.115, p.19-27, 2007.

OLIVEIRA, Newton C. de. A economia do sinistro: contribuição ao estudo dos acidentes de trabalho na indústria têxtil durante o Estado Novo, 1937-1945. Niterói: Dissertação de 
mestrado em História/UFF, 1993.

PERROT, Michelle. Os excluídos da História: operários, mulheres e prisioneiros. Rio de Janeiro: Paz e Terra, 2001.

PETERSEN, Sílvia. Levantamento da produção bibliográfica e de outros resultados de investigação sobre a história operária e o trabalho urbano fora do eixo Rio-Sáo Paulo. Cadernos AEL, v.14, n.26, p.257-344, 2009.

RAMAZZINI, Bernardino. As doenças dos trabalhadores. São Paulo: Fundacentro, 2000.

RIBEIRO, Herval Pina. A violência oculta do trabalho: as lesóes por esforços repetitivos. Rio de Janeiro: Editora Fiocruz, 1999.

SILVA, Maria Elisa Lemos Nunes da. Entre trilhos, andaimes e cilindros: acidentes de trabalho em Salvador (1934-1944). Salvador: Dissertação de Mestrado em História/UFBA, 1998.

THOMPSON, E. P. A formação da classe operária inglesa - 3 v. Rio de Janeiro: Paz e Terra, 1987.

THOMPSON, E. P. A miséria da teoria. Rio de Janeiro: Zahar, 1981.

VASCONCELLOS, Luís Calos Fadel de; PIGNATI, Wanderlei Antônio. Medicina do Trabalho: subciência ou subserviência? Uma abordagem epistemológica. Ciência \& Saúde Coletiva, v.11, n.4, p.1105-1115, 2006.

VIANNA, Luiz Werneck. Liberalismo e sindicato no Brasil. 4.ed.rev. Belo Horizonte:., Ed. UFMG, 1999. 